\title{
Erratum to: Amino acids and autophagy: their crosstalk, interplay and interlock
}

\author{
Chien-An A. Hu ${ }^{1} \cdot{\text { Zhenlong } \mathrm{Wu}^{2} \cdot \text { Junjun Wang }^{2}}^{2}$
}

Published online: 26 October 2015

(C) Springer-Verlag Wien 2015

\section{Erratum to: Amino Acids (2015) 47:2035-2036}

DOI 10.1007/s00726-015-2098-7

In the original publication of the article, Fig. 1a was wrongly published. The correct Fig. 1a is given below.

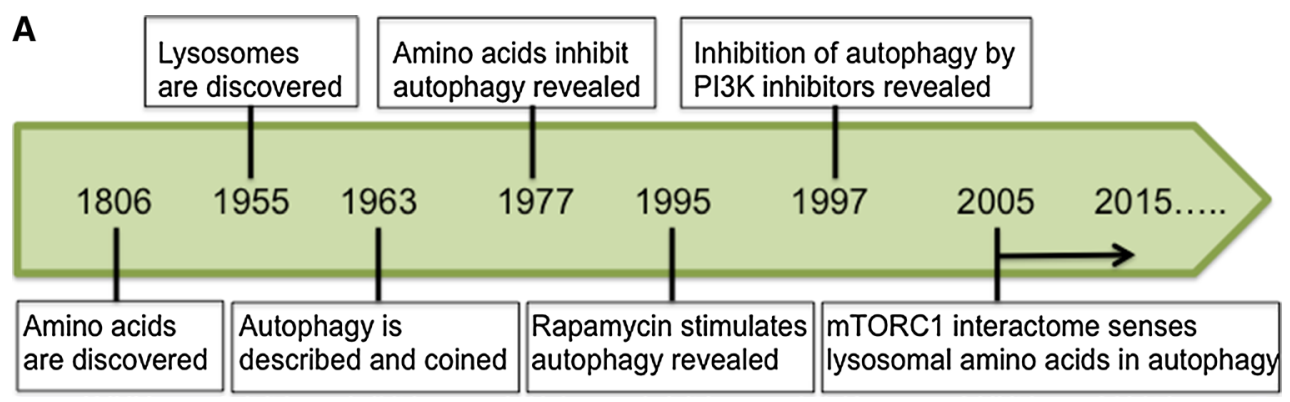

The online version of the original article can be found under doi:10.1007/s00726-015-2098-7.

Chien-An A. Hu

ahu@salud.unm.edu

1 Department of Biochemistry and Molecular Biology, University of New Mexico, Health Sciences Center, Albuquerque, NM 87131-0001, USA

2 State Key Laboratory of Animal Nutrition, College of Animal Science and Technology, China Agricultural University, Beijing 100193, People's Republic of China 